\title{
Detailed measurements of submicron particles from an Independence Day fireworks event in Albany, NY using HR-ToF-AMS
}

Jie Zhang ${ }^{1}$, Sara Lance ${ }^{1}$, Jeffrey M. Freedman ${ }^{1}$, Yele Sun ${ }^{2}$, Brian A. Crandall ${ }^{1}$, Xiuli Wei ${ }^{1,3}$, James J. Schwab ${ }^{1}$ ${ }^{1}$ Atmospheric Sciences Research Center, University at Albany, State University of New York, Albany, USA ${ }^{2}$ State Key Laboratory of Atmospheric Boundary Layer Physics and Atmospheric Chemistry, Institute of Atmospheric Physics, Chinese Academy of Sciences, Beijing, China

${ }^{3}$ Anhui Institute of Optics and Fine Mechanics, Chinese Academy of Sciences, Hefei, China

Corresponding author: Prof. James J. Schwab,E-mail: jschwab@albany.edu, Phone: +1 518-437-8754

This Supplemental Material file contains 17 pages with detailed information for the locations of the measurement sites, the lab calibration for $\mathrm{K}$ signals, the PMF results, the $\mathrm{K}$ emission estimation, etc., including 14 figures, 5 sections and references. 


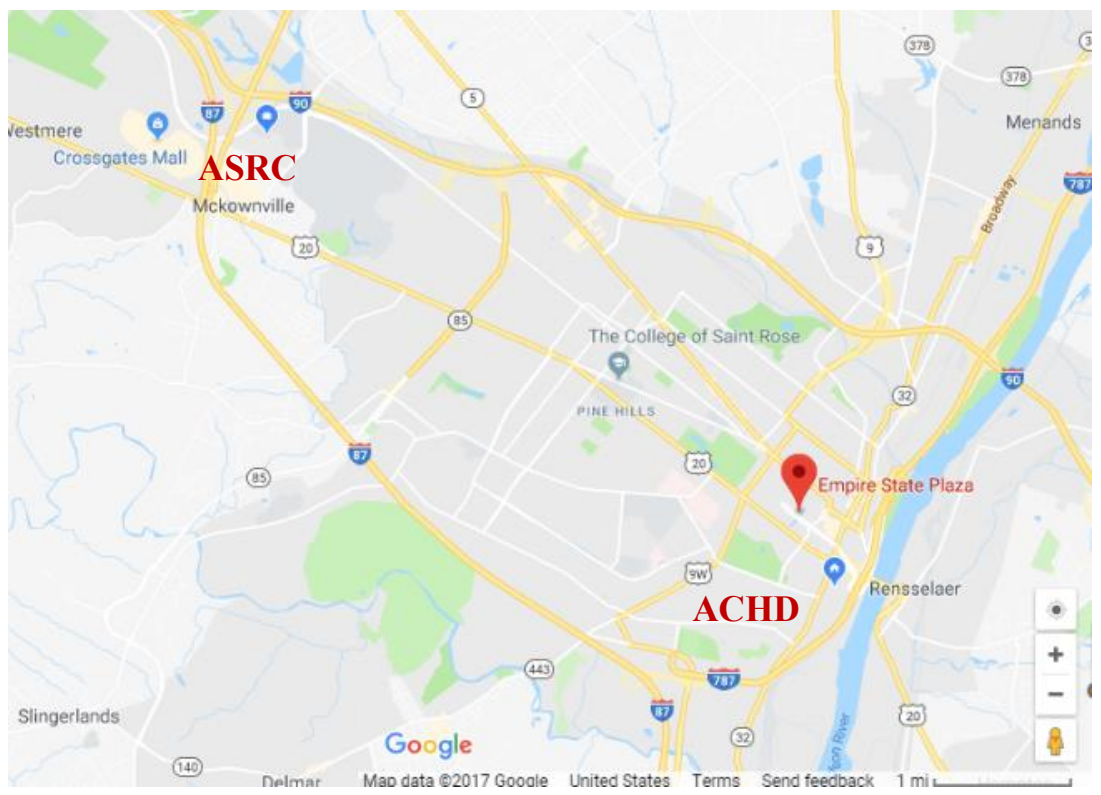

Figure S1. Locations of measurement sites (from Google maps)

ASRC: Atmospheric Sciences Research Center, University at Albany - the uptown site; ACHD: Albany County Health Department - downtown measurement site; Empire State Plaza: the fireworks burning location. 


\section{S1 Instrument setup and sampling information (ASRC site)}

These aerosol measurement instruments were located in a second floor lab and sampled from a common silica gel diffusion dryer (output $\mathrm{RH}<37 \%$ ), which was downstream from a PM2.5 cyclone and a $\sim 9$ m long sample duct with $10 \mathrm{~cm}$ inner diameter. The sample inlet is about 2 meters above the roof of Center for Environmental Sciences and Technology Management building (about $15 \mathrm{~m}$ above ground level). A supplemental airflow was continually drawn through the sample inlet, and aerosols were drawn from the centerline of this sample duct. After the sample duct, roughly $0.5 \mathrm{~m}$ of black conductive tubing ( $4.5 \mathrm{~mm}$ ID) was used to connect the duct with the dryer. After the dryer the flow was split three ways, connecting the SMPS, the HR-ToF-AMS and the PDR each with $0.3 \mathrm{~m}$ long, $4.5 \mathrm{~mm}$ ID sampling lines, which resulted in an estimated particle loss of less than $2 \%$ (https://www.mpic.de/en/research/particlechemistry/drewnick-group/projects/particle-loss-calculator-plc.html) ${ }^{1}$. 


\section{$\mathrm{S} 2$ High background values of $\mathrm{K}$ and $\mathrm{SO}_{4}$ for $\mathrm{HR}$-ToF-AMS chopper closed periods during the $\mathrm{FW}$ influenced period}
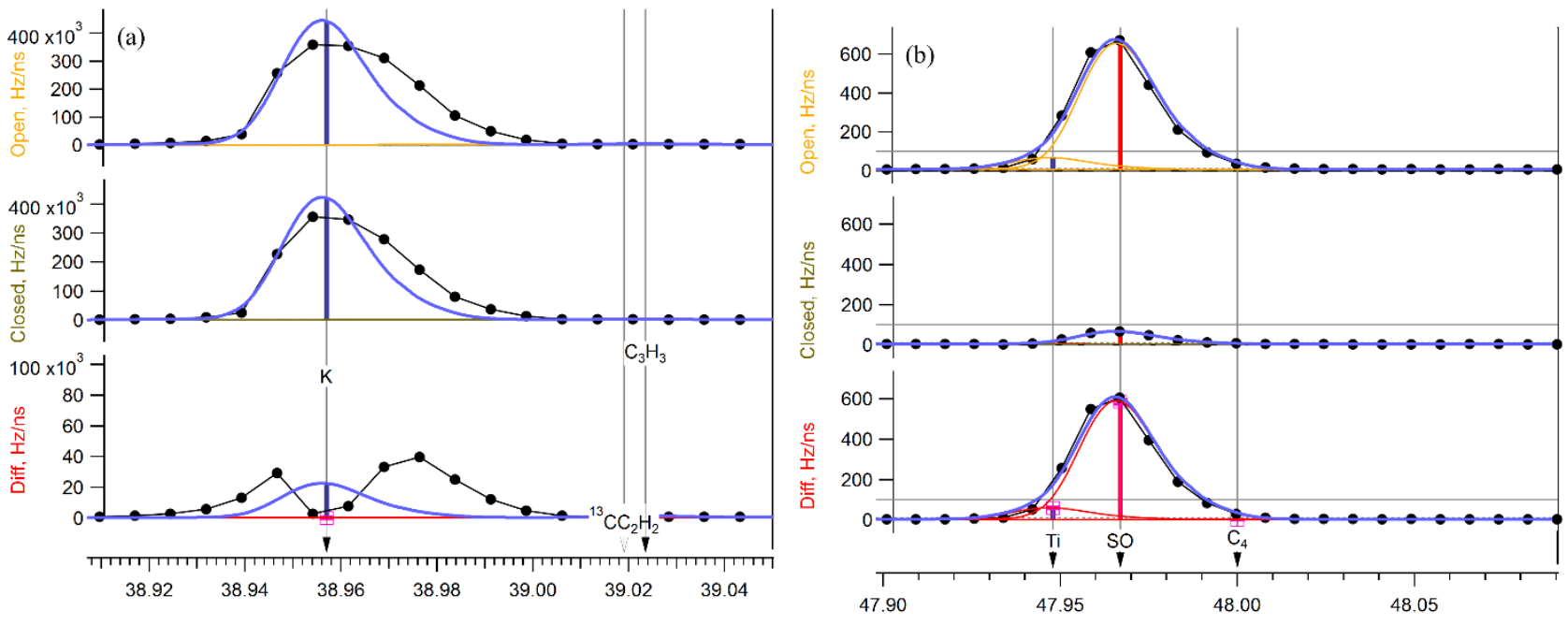

Figure S2. High-resolution mass spectra from the HR-ToF-AMS (Top: the mass spectra during chopper open mode; Middle: the mass spectra during chopper closed mode; Bottom: the difference between open and closed periods). (a) The $\mathrm{m} / \mathrm{z} 39\left({ }^{39} \mathrm{~K}^{+}\right)$ion peak at July 5 00:30; (b) the $\mathrm{m} / \mathrm{z} 48\left(\mathrm{SO}^{+}\right)$ion peak at July 5 00:30. (Black markers indicate the measured data, orange lines are Gaussian fitting lines for each ion, blue lines are the Gaussian fitting lines for the whole signal, gray vertical lines indicate the location of each ion, and different color vertical lines indicate the fitting height for each ion)

During the FW event period, the background value (chopper closed) of $\mathrm{SO}$ (the dominant ion fragment from $\mathrm{SO}_{4}$ ) increased to about $10 \%$ of the value with the chopper open, which is caused by the slow vaporization of $\mathrm{K}_{2} \mathrm{SO}_{4}$, which is common for refractory species. ${ }^{2}$ However, the background value of ${ }^{39} \mathrm{~K}^{+}$was almost equal to the chopper open value, which is caused by the surface ionization of $\mathrm{K}$, or the attachment of $\mathrm{K}$ to the ionizer walls followed by its slow removal ${ }^{3}$. As a result of this process there were not valid size distribution measurements for $\mathrm{K}$. Since $\mathrm{SO}_{4}$ does not suffer from interaction with the ionizer, its signal can be used to derive valid size distributions, as shown in Section 3.1 of the manuscript. 


\section{$\mathrm{S3}$ Estimation of $\mathrm{K}$ and $\mathrm{SO}_{4}$ mass concentrations during the $\mathrm{FW}$ influenced period}

The $\mathrm{CE}$ for both $\mathrm{K}$ and $\mathrm{SO}_{4}$ was determined using pure $\mathrm{K}_{2} \mathrm{SO}_{4}$ aerosols, produced from an aqueous solution by a TSI atomizer (Model 3076) and dried within a diffusion dryer to an average of $37 \%$ relative humidity, by comparing the AMS sulfate signal with the sulfate mass concentration determined by the SMPS. Designating the sulfate mass concentration derived from the SMPS measurements as $\mathrm{C}_{\mathrm{SO} 4}(\mathrm{SMPS})$ and the sulfate mass concentration derived from the AMS measurements (assuming a $\mathrm{CE}$ of 1 ) as $\mathrm{C}_{\mathrm{SO} 4}\left(\mathrm{AMS}, \mathrm{CE}=1\right.$ ), the actual $\mathrm{CE}$ for $\mathrm{SO}_{4}$ (and also for $\mathrm{K}$ ) is obtained from the ratio of $\mathrm{C}_{\mathrm{SO} 4}(\mathrm{AMS}, \mathrm{CE}=1)$ to $\mathrm{C}_{\mathrm{SO} 4}(\mathrm{SMPS})$, which yielded a $\mathrm{CE}$ of 0.15 for the pure $\mathrm{K}_{2} \mathrm{SO}_{4}$ used in this calibration. This CE was only used during the FW affected periods (07/02 21:00-07/03 04:00, 07/03 21:00-07/04 01:00, 07/04 21:00 to 07/05 08:00), periods during which the HR-ToF-AMS K raw signal was significantly elevated, to determine $\mathrm{K}, \mathrm{SO}_{4}, \mathrm{NO}_{3}$ and $\mathrm{Cl}$ mass concentrations. Otherwise, the nominal $\mathrm{CE}$ of 0.5 was used. We then derived $\mathrm{RIE}_{\mathrm{K}}$ in a similar manner based on the $\mathrm{K}_{2} \mathrm{SO}_{4}$ calibrations. $\mathrm{K}$ mass concentrations were derived from the SMPS measurements $\left(\mathrm{C}_{\mathrm{k}}(\mathrm{SMPS})\right)$, and calculations for $\mathrm{C}_{\mathrm{K}}(\mathrm{AMS}, \mathrm{RIE}=1)$ were derived from the AMS measurements using the calibrated $\mathrm{CE}$ of 0.15 . The ratio of $\mathrm{C}_{\mathrm{K}}(\mathrm{AMS}, \mathrm{RIE}=1)$ to $\mathrm{C}_{\mathrm{K}}(\mathrm{SMPS})$ yielded a value of 58 , which corresponds to an RIE of $\mathrm{K}$ for pure $\mathrm{K}_{2} \mathrm{SO}_{4}$ aerosol, as shown in the following equations based on the fundamental AMS mass concentration equation ${ }^{4}$.

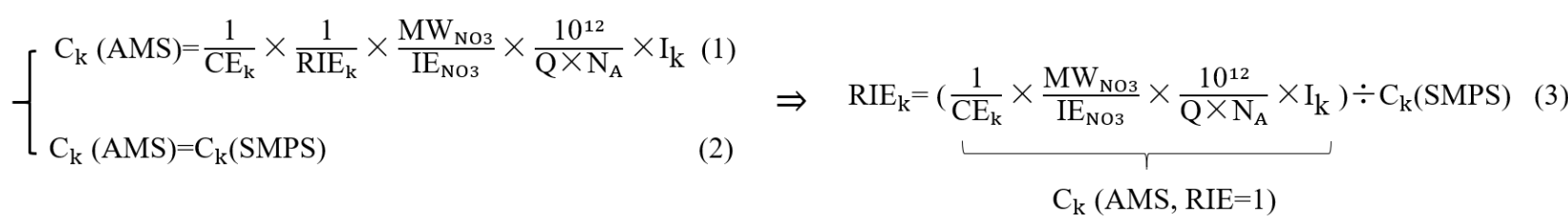

Where $\mathrm{RIE}_{\mathrm{K}}$ is the RIE of $\mathrm{K}, \mathrm{CE}_{\mathrm{K}}$ is the $\mathrm{CE}$ for $\mathrm{K}(0.15), \mathrm{MW}_{\mathrm{NO} 3}\left(62 \mathrm{~g} \mathrm{~mol}^{-1}\right)$ is the molecular weight of nitrate, $\mathrm{IE}_{\mathrm{NO}}$ (number of ions detected per molecule vaporized) is the ionization efficiency for nitrate, $10^{12}$ is used for unit conversion, $\mathrm{Q}$ is the flow rate, $\mathrm{N}_{\mathrm{A}}$ is Avogadro's number, and $\mathrm{I}_{\mathrm{k}}$ is the ion count rate for $\mathrm{K}$. Here $\mathrm{K}$ is sum of ${ }^{39} \mathrm{~K}^{+}$and ${ }^{41} \mathrm{~K}^{+}$. In this equation, $\mathrm{IE}_{\mathrm{NO} 3}, \mathrm{Q}$, and $\mathrm{I}_{\mathrm{K}}$ were obtained from the $\mathrm{HR}-\mathrm{ToF}-\mathrm{AMS}$ software, $\mathrm{CE}_{\mathrm{K}}$ was set to 0.15 , and we assumed that $\mathrm{C}_{\mathrm{K}}$ (AMS) was equal to the $\mathrm{K}$ mass concentration determined from SMPS measurements of the $\mathrm{K}_{2} \mathrm{SO}_{4}$ aerosol.

The $\mathrm{RIE}_{\mathrm{K}}$ determined using this method was 58 , an unusually high value. A value this high can only occur if the surface ionization of potassium adds significantly to the electron impact ionization efficiency. ${ }^{3}$ This does seem to be the case, as the potassium and sulfate mass concentrations determined with the laboratory determined values for CE (0.15) and $\mathrm{RIE}_{\mathrm{K}}(58)$ give consistent results with other instruments, as shown below. Based on the $\mathrm{RIE}_{k}(58)$ and CE (0.15), the 
maximum mass concentrations of $\mathrm{K}_{\text {and }} \mathrm{SO}_{4}$ during the $\mathrm{FW}$ significantly period on $7 / 4-5$ were $17.5 \mu \mathrm{g} \mathrm{m}{ }^{-3}$ and 18.5 $\mu \mathrm{g} \mathrm{m}^{-3}$, respectively, which yields a $\mathrm{K} / \mathrm{S}$ mass ratio of 2.8 , within $2 \%$ of the expected $\mathrm{K} / \mathrm{S}$ value of 2.75 for fireworks. ${ }^{5}$ Identical settings for all HR-ToF-AMS adjustable voltages were used for the laboratory calibration and the FW period measurements, especially the heater bias voltage (30V was used in calibration as well as the ambient measurements). This voltage is particularly important because the heater bias voltage is directly related to the $\mathrm{K}$ surface ionization process and improper settings will cause distortion of the ${ }^{39} \mathrm{~K}^{+}$peak in the mass spectra (Fig.S3) ${ }^{3}$. Taking this into account, when using an HR-ToF-AMS for future FW aerosol measurements, the heater bias voltage should be carefully set based on a pure $\mathrm{K}_{2} \mathrm{SO}_{4}$ calibration and checked during $\mathrm{FW}$ aerosol measurement periods to make sure the ${ }^{39} \mathrm{~K}^{+}$peak (chopper open) shows a "normal" shape like shown in Fig.S3b and Fig. S2a rather than the distorted shape illustrated in Fig. S3a.
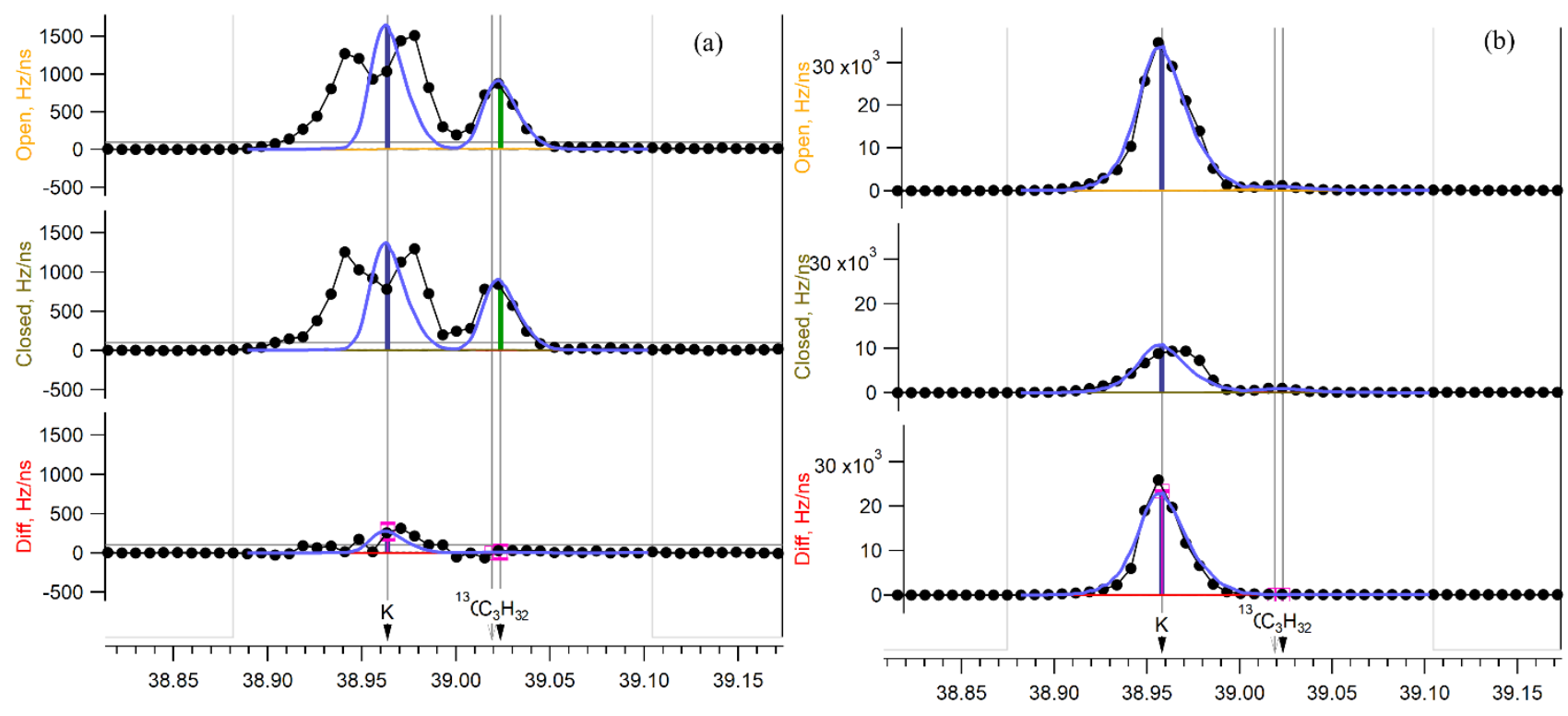

Figure S3. High-resolution mass spectra of the measurements of HR-ToF-AMS for K under different heater bias voltage settings during lab calibrations with $\mathrm{K}_{2} \mathrm{SO}_{4}$ (Top: the mass spectra from chopper open periods; Middle: the mass spectra from chopper closed periods; Bottom: the difference mass spectra between the above two). (a) heater bias voltage set to $31 \mathrm{~V}$; (b) heater bias voltage set to $30 \mathrm{~V}$. (Black markers indicate the measured data and blue lines are the Gaussian fitting lines)

Figures S4a and S4b show the "Diff ${ }^{39} \mathrm{~K}^{+}$signal" (open-closed) signals of July 42017 at noon and July 4 23:00. From the noon period to the FW period the signal increased by a factor of 80 (Fig. S4a vs. Fig. S4b), implying a significant influence from this FW display. However, the signal of "Diff ${ }^{39} \mathrm{~K}^{+}$" on the high-resolution mass spectra grew in magnitude and lost its Gaussian peak shape after July 5 00:30, and showed a "collapse" at the peak location as shown in Fig. S4c, which was clearly related to the very high levels of potassium in the AMS heater and ionizer regions, also 

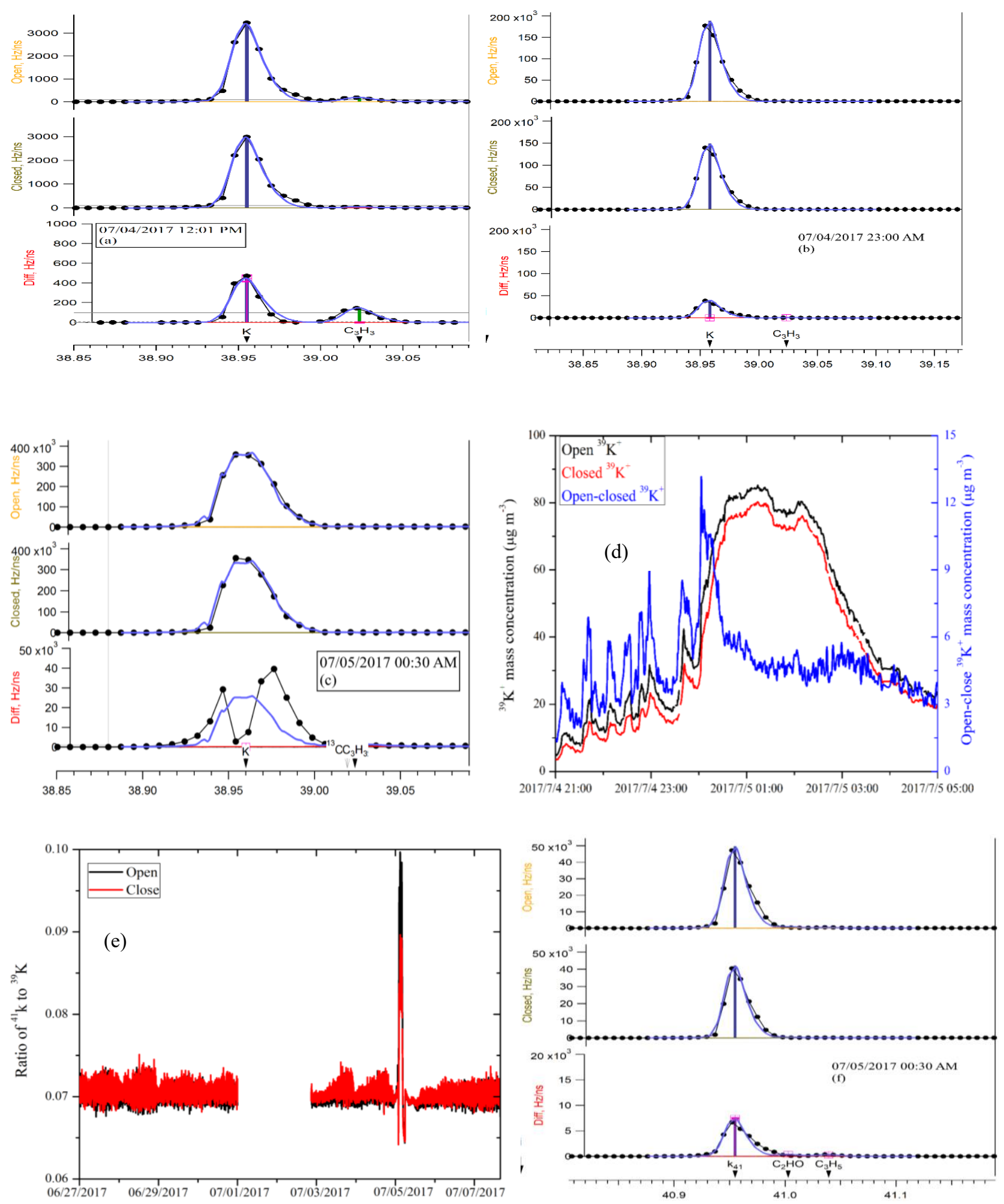

Figure S4. High-resolution mass spectra of the measurements of AMS (mass spectra from chopper open minus chopper closed). (a) the $\mathrm{m} / \mathrm{z} 39\left({ }^{39} \mathrm{~K}^{+}\right)$ion peak at 07/04 12:01 EDT; (b) the $\mathrm{m} / \mathrm{z} 39\left({ }^{39} \mathrm{~K}^{+}\right)$ion peak at July $423: 00$; (c) the $\mathrm{m} / \mathrm{z}$ $39\left({ }^{39} \mathrm{~K}^{+}\right)$ion peak at July 5 00:30; (d) the 1-min averaged time series of chopper open, closed and open-closed ${ }^{39} \mathrm{~K}^{+}$ mass concentration for the night of July 4-5. (e) the 1-min averaged time series of the isotope ratio of ${ }^{41} \mathrm{~K}^{+}$to ${ }^{39} \mathrm{~K}^{+}$for chopper open and close signals; (f) the $\mathrm{m} / \mathrm{z} 41\left({ }^{41} \mathrm{~K}^{+}\right)$ion peak at July 5 00:30. (Black markers indicate the measured data and red lines are the Gaussian fitting lines) 
illustrated in Fig. S4c, and S4d. Due to the accumulation of K on the vaporizer and the complicated dynamics which included surface ionization, the apparent mass concentration observed for $\mathrm{K}$ for chopper open and closed periods increased rapidly after 07/05 00:00 and kept a constant high value from 07/05 00:30 to about 02:30, and the highest open-close values occurred between 07/05 00:00 to 00:30. Under these conditions, directly fitting the "Diff ${ }^{39} \mathrm{~K}^{+}$signal" with a Gaussian function was unsuccessful. In addition, the method of fitting the closed and open high resolution spectra separately and subtracting the closed value from the open value was also problematic, as shown in Fig. S4e. Fig.S4e shows the isotope ratio of ${ }^{41} \mathrm{~K}^{+}$to ${ }^{39} \mathrm{~K}^{+}$for chopper open and closed was quite reasonable for non-FW influenced period (about 0.072), but rapidly increased after 07/05 00:00 until about 02:30. This failure to properly track the welldetermined isotope ratio makes it clear that the values determined for ${ }^{39} \mathrm{~K}^{+}$from open and closed mass spectra fitting were not correct during this period. We hypothesize that the problem with mass concentrations determined using $\mathrm{m} / \mathrm{z}$ of 39 for potassium during this period was caused by mass spectra saturation of ${ }^{39} \mathrm{~K}^{+}$signal due to sudden large quantities of $\mathrm{K}$ salts input into HR-ToF-AMS. For this case, the fragment table of the SQUIRREL software was modified to fit ${ }^{41} \mathrm{~K}$ by itself instead of including ${ }^{39} \mathrm{~K}$ as it normally would. Under these conditions, the peak for the "Diff ${ }^{41} \mathrm{~K}^{+}$isotope" was checked, and did show a reasonable Gaussian distribution (Fig. S4f), and could be fitted by the default Gaussian function. Based on this, the mass concentration of isotopic ${ }^{41} \mathrm{~K}^{+}$, calculated based on the RIE $=58$, $\mathrm{CE}=0.15$ and the isotopic ratio of 0.0722 , was used to estimate the mass concentration of ${ }^{39} \mathrm{~K}^{+}$. The summed concentrations of ${ }^{41} \mathrm{~K}^{+}$and ${ }^{39} \mathrm{~K}^{+}$were taken to be the $\mathrm{K}$ mass concentration in this study.

As described in the literature ${ }^{5-7}$, the $\mathrm{RIE}_{\mathrm{k}}$ can vary depend on the tuning of the spectrometer, especially the temperature of the vaporizer and the setting of the heater bias voltage (which strongly affects the surface ionization of K). From previous work, Slowik et al. (2010) used $\mathrm{KNO}_{3}$ to determine $\mathrm{RIE}_{\mathrm{k}}$ of 10 . This paper did not include information about the heater bias voltage setting ${ }^{6}$, which means it would be inappropriate to adopt this value for our measurements. Drewnick et al. (2015) estimated the $\mathrm{RIE}_{\mathrm{k}}$ to be 2.9 based on the ratio of K/S (2.75) from measured black powder ${ }^{5}$, and this value (2.9) was also used in Jiang et al. (2015) ${ }^{7}$. Using our calibrated $\mathrm{RIE}_{\mathrm{k}}$ and $\mathrm{CE}$ for $\mathrm{K}$ and $\mathrm{SO}_{4}$, we calculated the $\mathrm{K}$ and $\mathrm{SO}_{4}$ respectively from the HR-ToF-AMS mass spectrum, and resulted in a ratio of $\mathrm{K} / \mathrm{S}$ equal to 2.8, which was near to $2.75^{5}$ and confirms that our $\mathrm{RIE}_{\mathrm{k}}$ of 58 was suitable for this study. Considering these three quite different determinations for $\mathrm{RIE}_{\mathrm{K}}$, significant variation between instruments is expected and calibrations are needed. Building on our laboratory calibrations to determine $\mathrm{CE}$ and $\mathrm{RIE}_{\mathrm{K}}$, the AMS mass concentrations determined using these values are quite consistent with other measurements of mass concentration, as shown in Figure S9. This provides an extra measure of confidence in the unexpectedly high value determined for RIE . $_{\text {. }}$ 
Ambient aerosol density varies with composition, and an accurate determination of ambient aerosol mass concentration for the SMPS depends directly on density. At the same time, once density is determined, the SMPS data can be used to provide an independent measure of submicron aerosol mass for comparison with concentrations determined by the AMS. Assuming the ambient background $\mathrm{SO}_{4}, \mathrm{NO}_{3}$, and $\mathrm{Cl}$ would not change during the $\mathrm{FW}$ event, the aerosol during this event could be broken down into predominantly $\left(\mathrm{NH}_{4}\right)_{2} \mathrm{SO}_{4}, \mathrm{NH}_{4} \mathrm{NO}_{3}, \mathrm{~K}$ salts (such as $\mathrm{K}_{2} \mathrm{SO}_{4}, \mathrm{KNO}_{3}, \mathrm{KCl}$ ), and organics. We also assume the BC contribution to total concentration was constant for the ACHD and ASRC sites. Using the densities of organics as $1.4 \mathrm{~g} \mathrm{~cm}^{-3},\left(\mathrm{NH}_{4}\right)_{2} \mathrm{SO}_{4}$ as $1.79 \mathrm{~g} \mathrm{~cm}^{-3}, \mathrm{NH}_{4} \mathrm{NO}_{3}$ as $1.72 \mathrm{~g} \mathrm{~m}^{-3}, \mathrm{~K}_{2} \mathrm{SO}_{4}$ as $2.66 \mathrm{~g} \mathrm{~m}^{-3}, \mathrm{KNO}_{3}$ as $2.11 \mathrm{~g} \mathrm{~m}^{-3}, \mathrm{KCl}$ as $1.99 \mathrm{~g} \mathrm{~m}^{-3}$, and $\mathrm{BC} 1.8 \mathrm{~g} \mathrm{~m}^{-3}, 8,9$ the averaged $\mathrm{FW}$ aerosol density was then calculated from

$$
\rho_{\text {ambient }}=\frac{m_{\text {Total }}}{\frac{m_{\text {organic }}}{\rho_{\text {organic }}}+\frac{m_{\left(\mathrm{NH}_{4}\right)_{2} \mathrm{SO}_{4}}}{\rho_{\left(\mathrm{NH}_{4}\right)_{2} \mathrm{SO}_{4}}}+\frac{m_{\mathrm{NH}_{4} \mathrm{NO}_{3}}}{\rho_{\mathrm{NH}_{4} \mathrm{NO}_{3}}}+\frac{m_{K_{2} \mathrm{SO}_{4}}}{\rho_{\mathrm{K}_{2} \mathrm{SO}_{4}}}+\frac{m_{K N O_{3}}}{\rho_{K N O_{3}}}+\frac{m_{K C l}}{\rho_{\mathrm{KCl}}}+\frac{m_{B C}}{\rho_{B C}}}
$$

Where $\boldsymbol{\rho}$ is density and $\boldsymbol{m}$ 's are the mass concentrations(determined by the AMS except for BC). During the Independence Day FW event period, the density reached values as high as $2.0 \mathrm{~g} \mathrm{~m}^{-3}$, highlighting the influence of the inorganic compounds from FW displays. Using the ambient aerosol densities determined above with the SMPS volume distributions, Figure S5a shows the correlation between SMPS measurements of mass concentrations and the HR-ToFAMS measurements for the whole period (from June 27 to July 7 2017). A high correlation $\left(\mathrm{r}^{2}=0.98\right)$ with a slope of 1.14 increases the confidence in use of the above $\operatorname{RIE}_{K}(58)$ and $\mathrm{CE}(0.15)$ for $\mathrm{K}$, and $\mathrm{CE}(0.15)$ for $\mathrm{K}$-salt related compounds $\left(\mathrm{SO}_{4}, \mathrm{NO}_{3}\right.$, and $\mathrm{Cl}$ ) influenced by $\mathrm{FW}$ events. When calculating the SMPS mass concentration, the aerosols were assumed to be spherical and with a dynamic shape factor of 1 , which may cause some uncertainty. To estimate this potential error, the "Jayne shape factor" was calculated based on the AMS measured mass size distribution and SMPS measured mass size distribution as follows ${ }^{10}$,

$\mathrm{S}=\frac{d_{v a}}{d_{m}} \times \frac{\rho_{0}}{\rho_{m}}$

Where $\mathrm{S}$ is the Jayne shape factor, which is proportional to the aerosol dynamic shape factor ${ }^{10}, \mathrm{~d}_{\mathrm{va}}$ is the aerosol vacuum aerodynamic diameter measured by HR-ToF-AMS, $d_{m}$ is the aerosol electrical mobility diameter measured by SMPS, $\rho_{0}$ is the standard density of $1.0 \mathrm{~g} \mathrm{~cm}^{-3}$, and $\rho_{\mathrm{m}}$ is the density of the material in the particle. ${ }^{10}$ Due to the observed externally mixed character of this aerosol (different mode diameters for inorganic and organic compounds as shown in Figures 3 and S13), the shape factors for inorganic and organic were estimated separately. For inorganics, the peak mode for the averaged SMPS measured mass size distribution during the FW influenced period (about $290 \mathrm{~nm}$, Fig. 


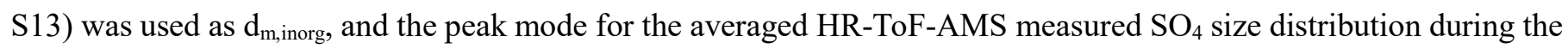
FW influenced period (about $600 \mathrm{~nm}$, Fig. 3) was used as $d_{v a, \text { inorg. }} \rho_{\mathrm{m} \text {,inorg }}$ was equal to the averaged FW aerosol inorganic density calculated from Eq. (4) $\left(2.20 \mathrm{~g} \mathrm{~cm}^{-3}\right)$. With these values, Equation 5 gave a $S_{\text {inorg }}$ of about 0.94 . For organics, the secondary peak from SMPS measured mass size distribution during the FW influenced period was less clear, so the 07/04 daytime measured SMPS mass mode diameter was used based on the consideration that organics was the main component of this aerosol (about $87 \%$, in Fig. 2). Then $\mathrm{d}_{\mathrm{m} \text {,org }}$ was equal to the peak mode for averaged SMPS measured mass size distribution during the 07/04 daytime (about $250 \mathrm{~nm}$, Fig. S13), and $\mathrm{d}_{\mathrm{va}, \text { org }}$ was equal to the peak mode for the averaged HR-ToF-AMS measured organic size distribution during 07/04 daytime (about $350 \mathrm{~nm}$, Fig. S13). With these input values, and a density of $1.40 \mathrm{~g} \mathrm{~cm}^{-3}$ for organics, $\mathrm{S}_{\text {org }}$ was calculated to be indistinguishable from 1.0. Applying these shape factors into SMPS measured mass concentration causes an increase in the slope of Fig. S5a from 1.14 to 1.19 . This roughly $19 \%$ difference between AMS and SMPS mass concentrations is a decent estimate of the uncertainty for these measurements, which, in addition to the usual error sources (flows, instrument parameters, etc.), also include the unique to this study $\mathrm{CE}$ of pure $\mathrm{K}_{2} \mathrm{SO}_{4}$ from our lab calibration and the use of this CE for K-salt related compounds for the FW events.
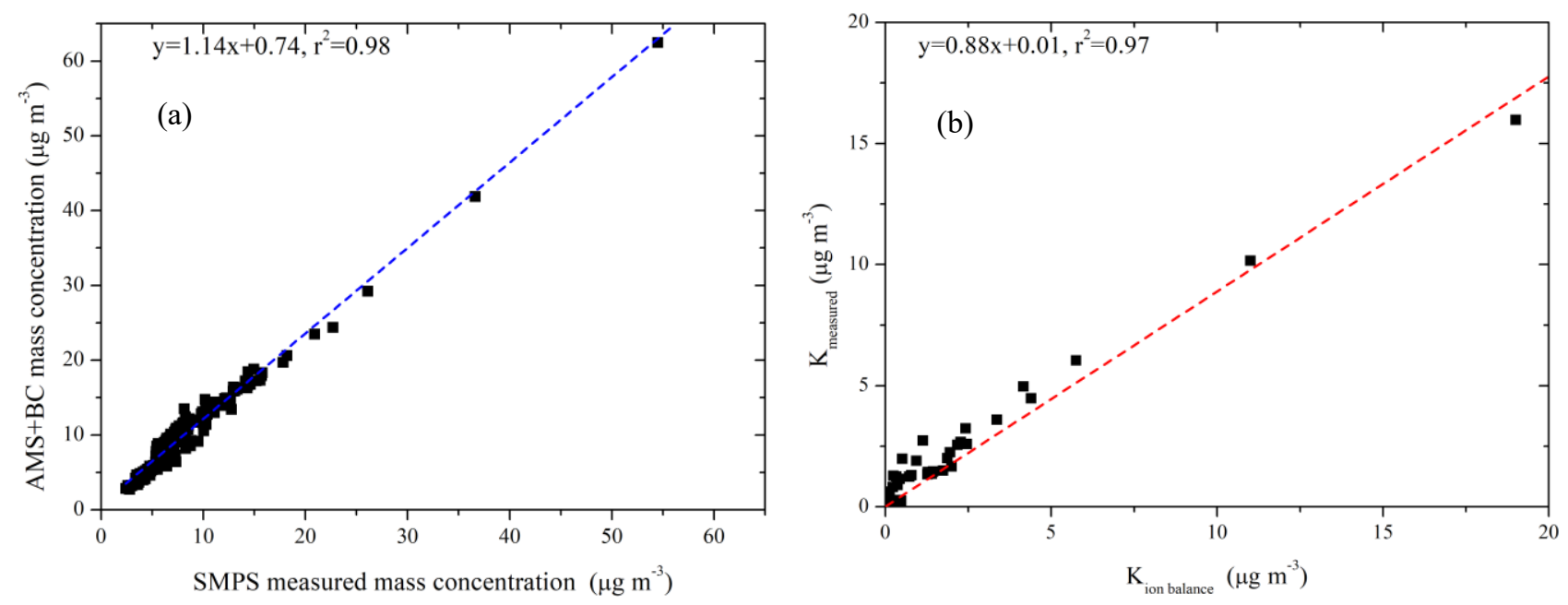

Figure S5. The correlation between (a) the reported mass concentration by HR-ToF-AMS and by SMPS from June 27 2017 to July 72017 (including the FW periods); (b) the K needed to balance charge for inorganic compounds $\left(\mathrm{SO}_{4}, \mathrm{Cl}\right.$, and $\mathrm{NO}_{3}$ ) and the HR-ToF-AMS measured $\mathrm{K}$. 

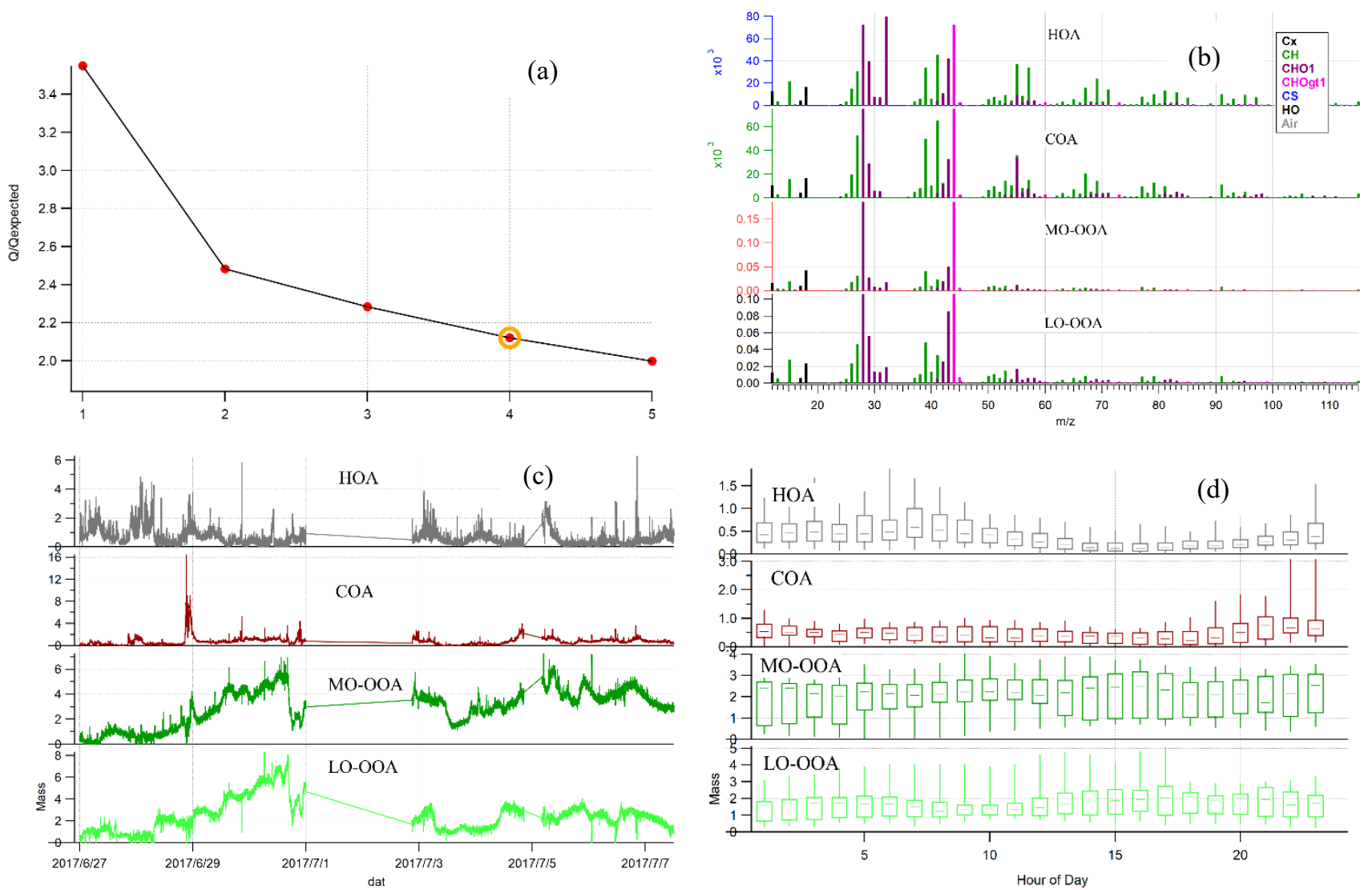

Figure S6. a): The PMF quality of fit parameter $\left(\mathrm{Q} / \mathrm{Q}_{\text {expected }}\right)$ as a function of the number of factors; $\left.b\right)$ : mass spectra of four identified OA component factors; $c$ ): the time series of mass concentration of each organic aerosol factor; $d$ ): mass concentration diurnal variation of each organic aerosol factor. 

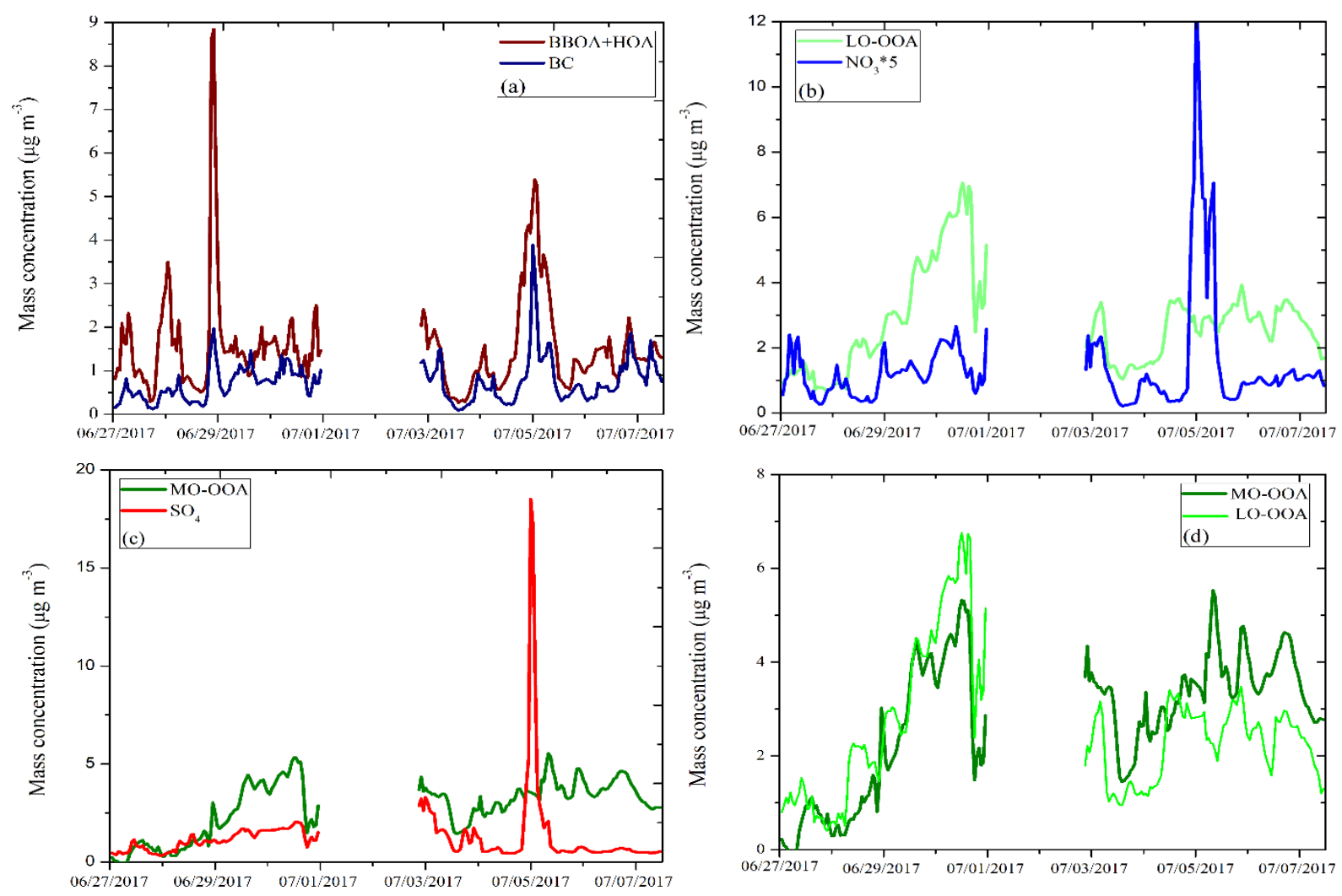

Figure S7. The time series of mass concentrations of (a) BBOA+HOA (measured at ASRC site) and BC (measured at ACHD site); (b): LO-OOA and $\mathrm{NO}_{3} * 5$; (c) MO-OOA and $\mathrm{SO}_{4}$;(d) MO-OOA and LO-OOA.

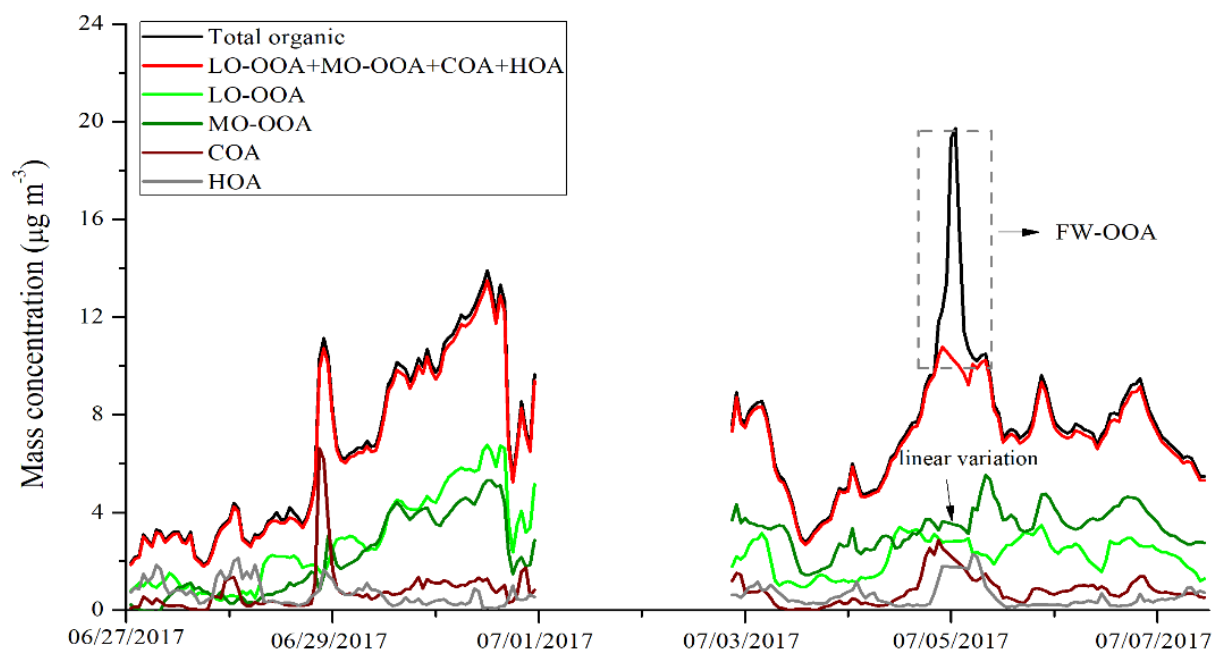

Figure S8. The time series of $1 \mathrm{~h}$ mass concentration of the four organic aerosol factors determined by the PMF analysis, their sum and the total organic from 06/27/2017 to 07/07/2017. 


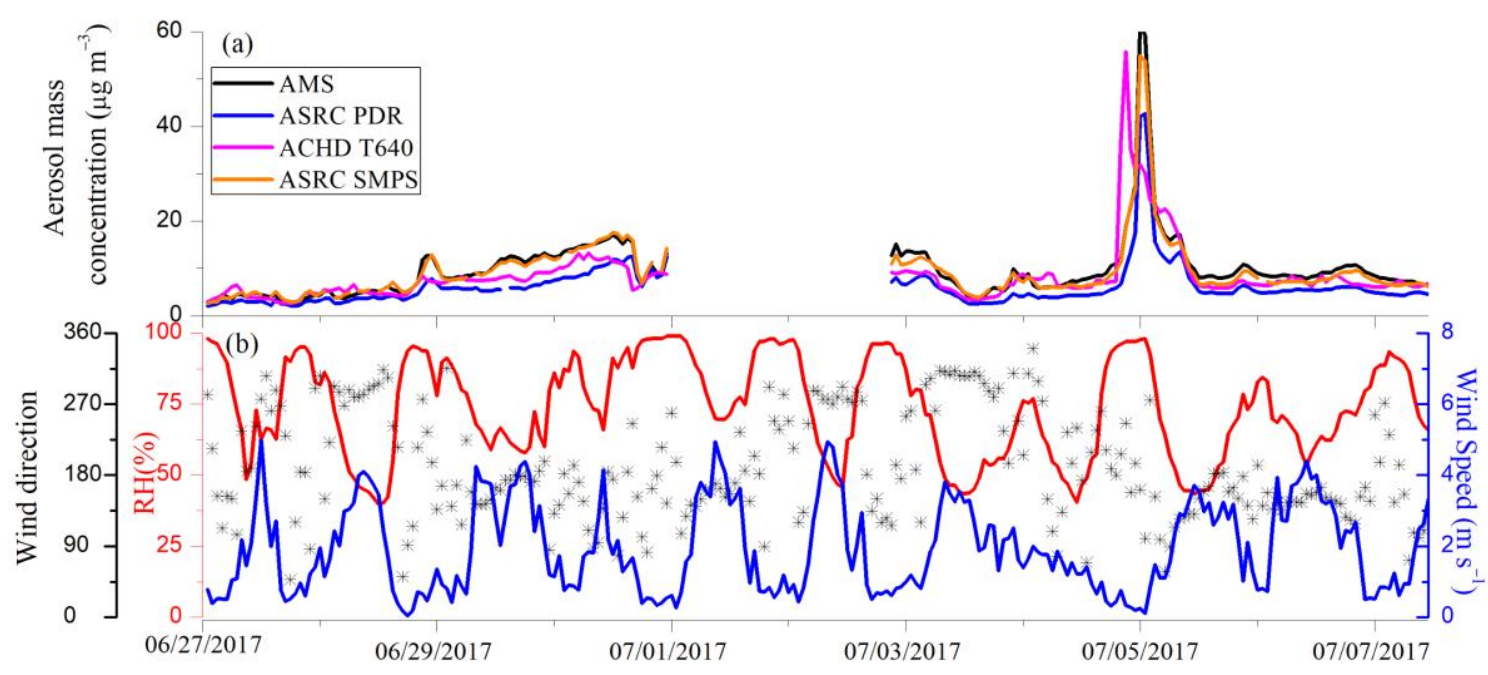

Figure S9. Time series of (a) aerosol hourly-averaged mass concentration measured by ASRC AMS (PM 1 ), PDR $\left(\mathrm{PM}_{2.5}\right)$, and ACHD T640 $\left(\mathrm{PM}_{2.5}\right)\left(\mu \mathrm{g} \mathrm{m}^{-3}\right)$; (b) NYSM meteorological parameters, with relative humidity (\%), wind direction, and wind speed $\left(\mathrm{m} \mathrm{s}^{-1}\right)$.
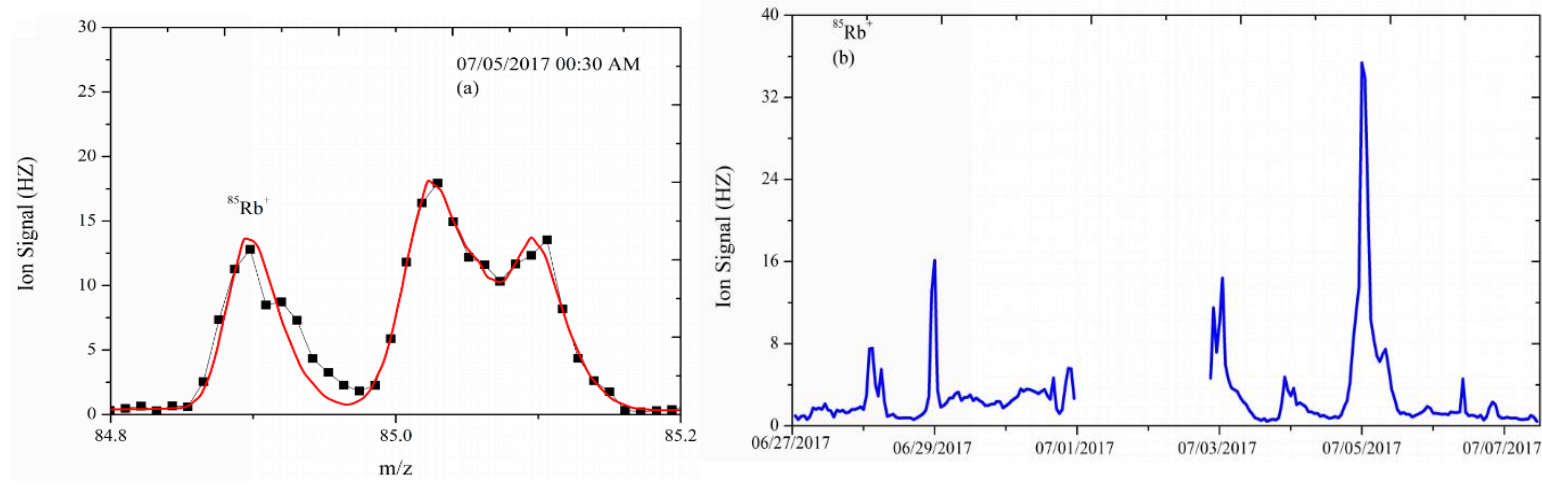

Figure S10. (a) The $\mathrm{m} / \mathrm{z} 85\left({ }^{85} \mathrm{Rb}^{+}\right)$ion peak at 07/05 00:30 pm; (b) the time series of $\mathrm{Rb}$ ion signal during the measurement period.
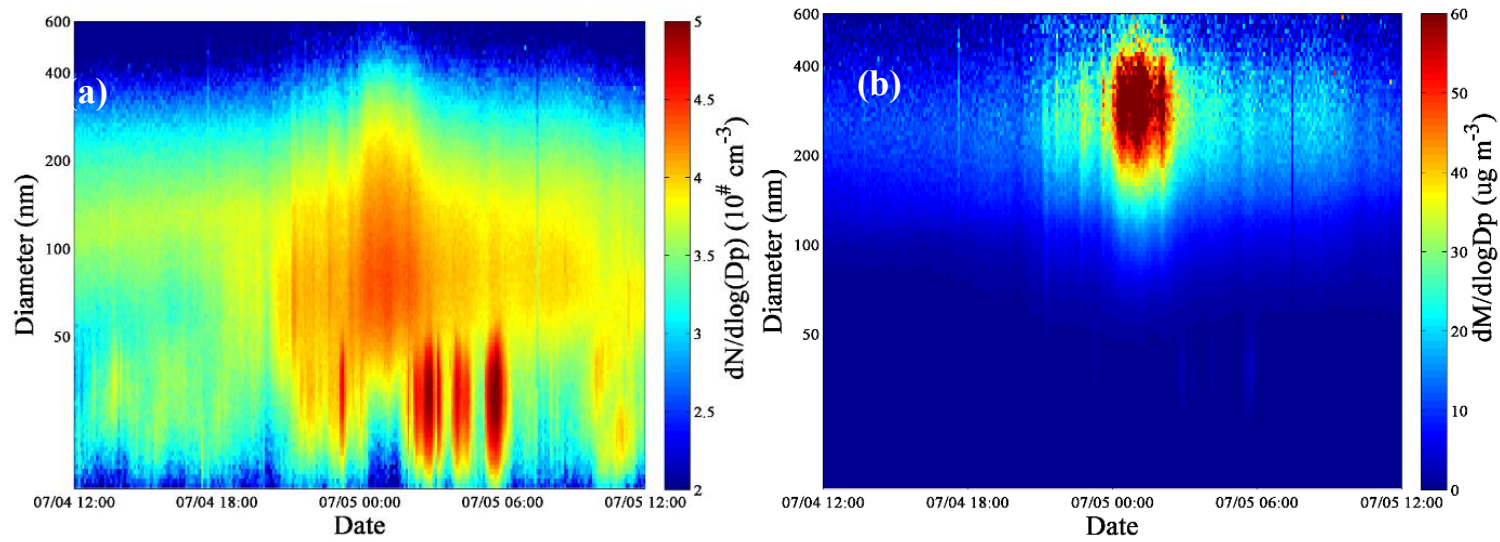

Figure S11. (a): Aerosol number size distribution (mobility diameter) measured by SMPS from July 4 12:00 to July 5 12:00; (b) aerosol mass size distribution measured by SMPS for the same time period. 


\section{S5 Estimation of FW aerosol from Albany Empire State Plaza FW display}

The Gaussian dispersion equation for single point source was used (http://courses.washington.edu/cee490/PlumeD4.pdf), as shown:

$\mathrm{C}(\mathrm{x}, \mathrm{y}, \mathrm{z})=\frac{\mathrm{Q}}{2 \pi \mathrm{u} \sigma_{\mathrm{y}} \sigma_{\mathrm{z}}} \times \exp \left(\frac{-\left(\mathrm{y}-\mathrm{y}_{0}\right)^{2}}{2 \sigma_{\mathrm{y}}}\right) \times \exp \left(\frac{-\left(\mathrm{z}-\mathrm{z}_{0}\right)^{2}}{2 \sigma_{\mathrm{z}}}\right)$

Here, $y_{0}$ represents the initial location of FW plume, $z_{0}$ represents the initial height of FW plume, Q is emission strength of source $\left(\mathrm{g} \mathrm{s}^{-1}\right), \mathrm{u}$ is average wind speed thru the plume $\left(\mathrm{m} \mathrm{s}^{-1}\right), \mathrm{C}$ is the measured concentration $\left(\mathrm{g} \mathrm{m}^{-3}\right)$, and $\sigma_{\mathrm{y}}$ and $\sigma_{\mathrm{z}}$ represent the horizontal and vertical standard deviations in meters.

In this study, for the location at ASRC, we simply assume the emission height of the FW to be equal to the relative vertical location of ASRC (in comparison to the Empire State Plaza, taking into account the relative altitudes and height of sample inlets above ground), and $\mathrm{y}$ and $\mathrm{y}_{0}$ were assumed to be zero. At the same time, $\mathrm{u}$ is the estimated advection speed of $1 \mathrm{~m} \mathrm{~s}^{-1}, \sigma_{\mathrm{z}}$ was taken as the vertical mixed height (about $200 \mathrm{~m}$, as shown in Fig. 6), $\sigma_{\mathrm{y}}$ was estimated to be about $300 \mathrm{~m}$ based on the result of Turner ${ }^{11}, \mathrm{C}$ is then the maximum hourly value of $\mathrm{FW}$ mass concentration at the ASRC site (about $50 \mu \mathrm{g} \mathrm{m}^{-3}$ after deducting background aerosol concentration), so Q could be estimated using $\mathrm{Q}=2 \pi \sigma_{\mathrm{y}} \sigma_{\mathrm{z}} \mathrm{C}$, and would be about $19 \mathrm{~g} \mathrm{~s}^{-1}$ (or about $70 \mathrm{~kg}$ emitted in a typical hour). Assuming the length of the FW event to be one half hour, the total aerosol emission from FW the display at Albany would be about $35 \mathrm{~kg}$. Here we only estimated the plume near the ground and assume that we sampled from the center of plume rather from the edge, and ignored plumes at higher altitudes (like the one near $400 \mathrm{~m}$, as shown in Fig. 6). These assumptions and omissions increase the uncertainty. Based on the estimate of total firework mass (2000 - 10,000 kg), an estimated emission factor of 0.07 for $\mathrm{PM}_{10}$ from Camilleri et al. ${ }^{12}$, the estimated aerosol mass emission should be about 140-700 $\mathrm{kg}$ for all FW in the event. Our Gaussian plume estimate is lower than this by about $75-95 \%$. Due to the uncertainties for both estimation methods, total fireworks mass and the emission factor, $35 \mathrm{~kg}$ was still considered to be reasonable. 


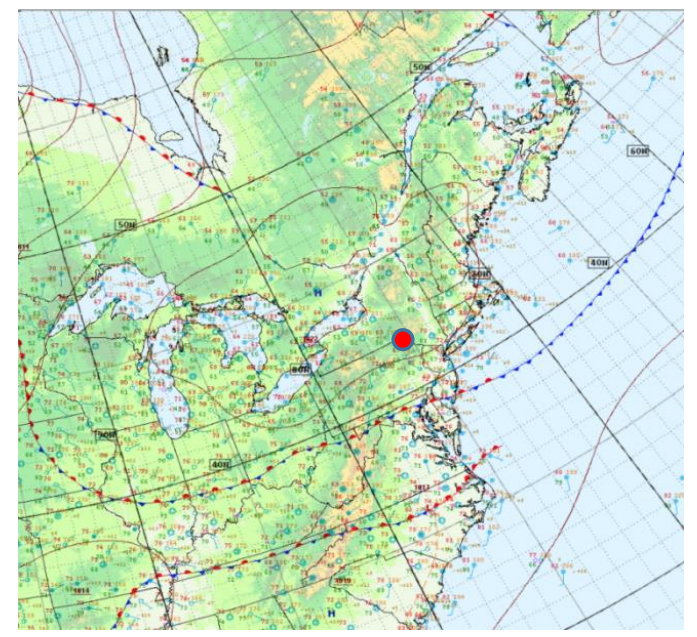

Figure S12. The surface weather map for the Northeastern United States for July $4^{\text {th }}$ 23:00 (red circle indicates the location of Albany, https://www.wpc.ncep.noaa.gov/html/sfc-zoom.php)
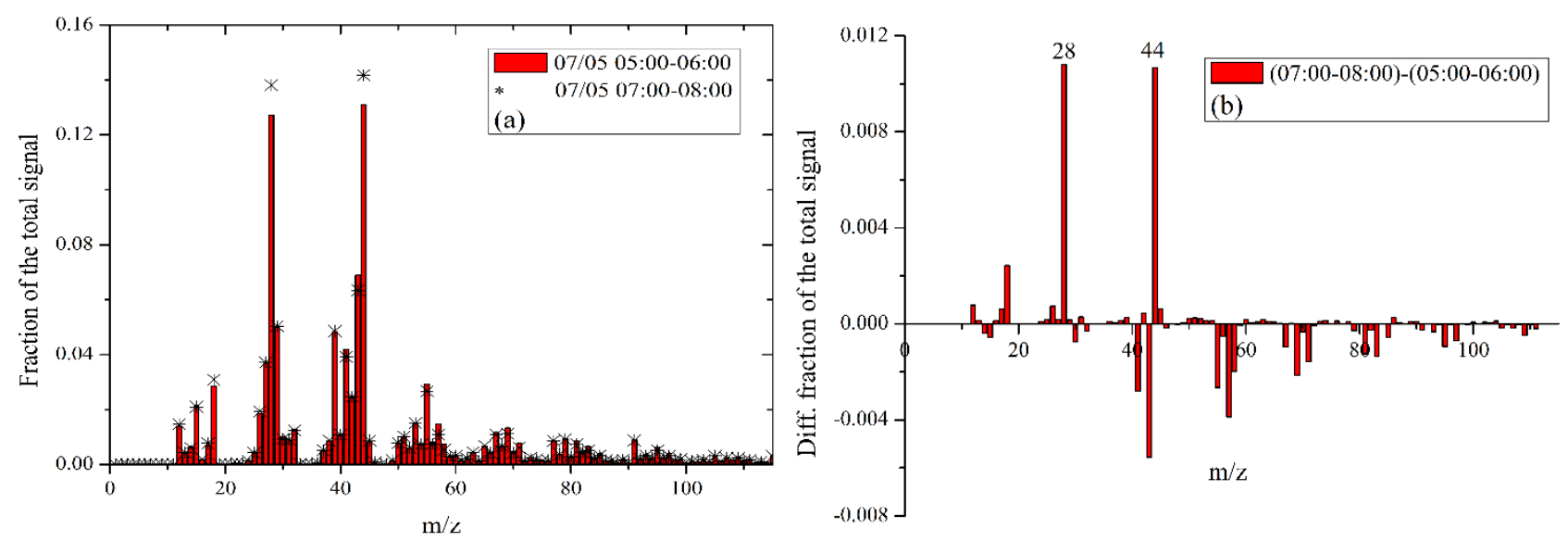

Figure S13. (a) AMS organic mass spectra of July 5 05:00-06:00 and July 5 07:00-08:00; (b) the spectra difference between these two periods.

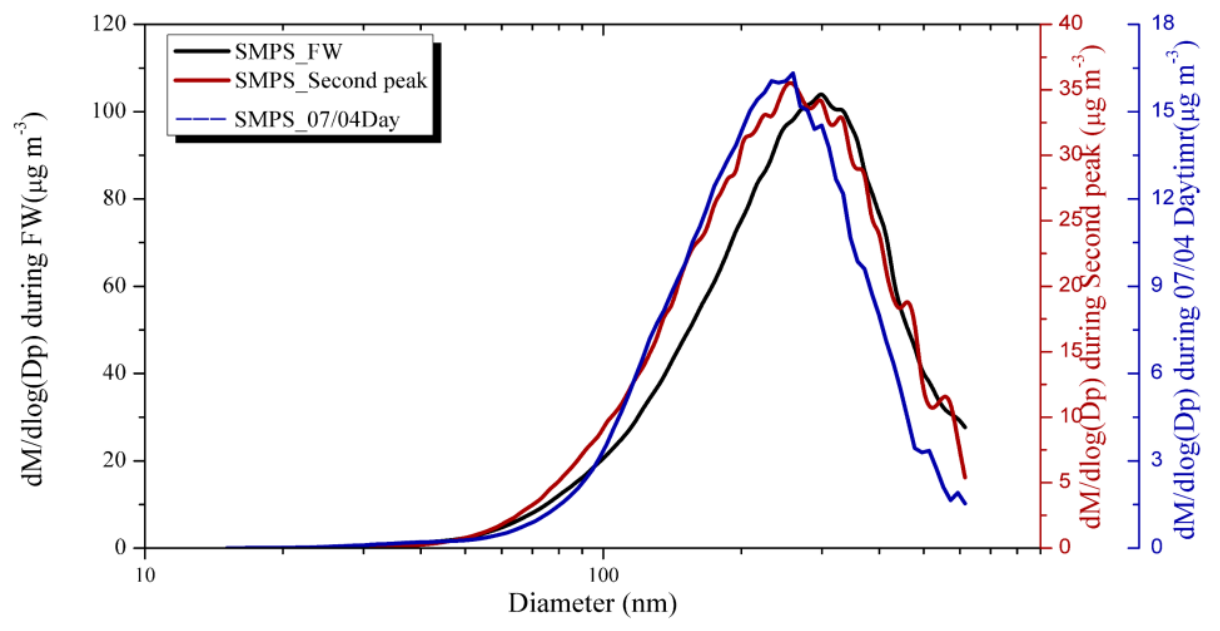

Figure S14. SMPS-measured total mass size distribution (mobility diameter) during the FW event (July 4 23:00 to July 5 03:00), during July 4 daytime (09:00 to 17:00), and the second peak hour (July 5 07:00-08:00). 


\section{References:}

(1). von der Weiden, S. L., Drewnick, F., and Borrmann, S. Particle Loss Calculator - a new software tool for the assessment of the performance of aerosol inlet systems. Atmos. Meas. Tech. 2009, 2, 479-494, doi:org/10.5194/amt-2-479-2009.

(2). Salcedo, D., Onasch, T. B., Aiken, A. C., Williams, L. R., de Foy, B., Cubison, M. J., Worsnop, D. R., Molina, L. T., and Jimenez, J. L. Determination of particulate lead using aerosol mass spectrometry: MILAGRO/MCMA2006 observations, Atmos. Chem. Phys., 2010, 10, 5371-5389, doi:org/10.5194/acp-10-5371-2010, 2010.

(3). Drewnick, F., Diesch, J. M., Faber, P., and Borrmann, S. Aerosol mass spectrometry: particle-vaporizer interactions and their consequences for the measurements. Atmos. Meas. Tech. 2015, 8, 3811-3830, doi:org/10.5194/amt-83811-2015.

(4). Takegawa, N., Miyazaki, Y., Kondo, Y., Komazaki, Y., Miyakawa, T., Jimenez, J. L., Jayne, J. T., Worsnop, D. R., Allan, J. D., and Weber, R. J. Characterization of an Aerodyne Aerosol Mass Spectrometer (AMS): Intercomparison with Other Aerosol Instruments. Aerosol Sci. Technol. 2005, 39:760-770, doi: $10.1080 / 02786820500243404$.

(5). Drewnick, F., Hings, S. S., Curtius J, Eerdekens, G., and Williams, J. Measurement of fine particulate and gasphase species during the New Year's fireworks 2005 in Mainz, Germany. Atmos. Environ. 2006, 40, 4316-4327, doi:10.1016/j.atmosenv.2006.03.040.

(6). Slowik, J. G., Stroud, C., Bottenheim, J. W., Brickell, P. C., Chang, R. Y.-W., Liggio, J., Makar, P. A., Martin, R. V., Moran, M. D., Shantz, N. C., Sjostedt, S. J., Donkelaar A. van, Vlasenko A., Wiebe, H. A., Xia, A. G., Zhang, J., Leaitch, W. R., Abbatt. J. P. D. Characterization of a large biogenic secondary organic aerosol event from eastern Canadian forests. Atmos. Chem. Phys. 2010, 10, 2825-2845, doi:10.5194/acp-10-2825-2010.

(7). Jiang, Q., Sun, Y. L., Wang, Z., Yin, Y. Aerosol composition and sources during the Chinese Spring Festival: fireworks, secondary aerosol, and holiday effects. Atmos. Chem. Phys. 2015, 15, 6023-6034, doi:10.5194/acp-156023-2015.

(8). Zhang, Q., Canagaratna, M. R., Jayne, J. T., Worsnop, D. R., and Jimenez, J. L. Time-and size-resoMOed chemical composition of submicron particles in Pittsburgh: Implications for aerosol sources and processes. J. Geophys. Res. Atmos. 2005, 110, D07S09, 1-19, doi:10.1029/2004JD004649.

(9). Lee, B. P., Li, Y. J., Flagan, R. C., Lo, C., and Chan, C. K. Sizing characterization of the fast-mobility particle sizer (FMPS) against SMPS and HR-ToF-AMS. Aerosol Sci. Technol. 2013, 47, 1030-1037, 
doi:10.1080/02786826.2013.810809.

(10). DeCarlo, P. F., Slowik, J. G., Worsnop, D. R., Davidovits, P., Jimenez, J. L. Particle morphology and density characterization by combined mobility and aerodynamic diameter measurements. Part 1: Theory. Aerosol Sci. Technol. 2004, 38, 1185-1205.

(11). Turner, D. B. Workbook of atmospheric dispersion estimates: an introduction to dispersion modeling. CRC press 1994.

(12). Camilleri, R., Vella, A.J. Emission Factors for Aerial Pyrotechnics and Use in Assessing Environmental Impact of Firework Displays: Case Study from Malta. Propellants Explos. Pyrotech. 2016, 41, 273-280, doi: 10.1002/prep.201500205 